\title{
Indigenous multilingualisms past and present
}

\author{
Jill Vaughan and Ruth Singer \\ Research Unit for Indigenous Language, University of Melbourne
}

\section{Introduction}

Although multilingualism has been the norm throughout human history, we still know very little about the full range of societal multilingualisms. To flesh out the picture, this special issue considers Indigenous contexts where the hierarchical models of multilingualism often naturalised by nation states play a more marginal role (e.g. Fishman 1967; Lüpke 2015, 2016). Current discussions of multilingualism may treat sociolinguistic complexity or 'superdiversity' (e.g. Blommaert 2013; Vertovek 2006) as a relatively new phenomenon; a product of our increasingly mobile and diverse era. Yet these conditions, that have long existed in more 'peripheral' local language communities, seem to be simply going "mainstream at the metropole" (Silverstein 2015: 7). Attention to multilingualism in Indigenous contexts tends to focus exclusively on the dynamics between local languages on the one hand and new languages that grow or come into being as a result of colonialism on the other, such as English, Portuguese, Nheengatú or Australian Kriol.

In some regions there has been early and continuing attention to Indigenous multilingualism, such as in Americanist work on pre-contact cross-language dynamics, established in the Boasian tradition of anthropological linguistics (Kroskrity, Epps). However, in general there has been a lack of attention to relations between Indigenous languages. These dynamics can be overshadowed by a focus on colonial-Indigenous relations or rendered invisible by assumptions about traditional life informed by linguistic nationalism. As the papers in this special issue show, intra-Indigenous multilingualisms are an integral part of intra-Indigenous relations more generally, and distinct from colonial-Indigenous relations. For example, Epps notes that while code-switching between Hup and Portuguese is common, code-switching between Hup and another Indigenous language would evoke strong censure (cf. Vaughan in press). The papers in this issue contextualise Indigenous multilingualisms, revealing the ways that multiple Indigenous languages come to be deeply embedded into the fabric of daily life. Some reflect on the effects of linguistic work on local language ideologies, such as classifications of Indigenous languages and the valorisation of certain Indigenous languages by missionaries or governments (Narayanan, Vaughan).

The papers in this issue compare observations about contemporary multilingualism with records of multilingualism from earlier contact eras and reconstructions of pre-contact patterns of language use. Intensely multilingual ecologies have been reported at various times and places within the present-day United States, Australia, South America, Melanesia, and West Africa. Many of the Indigenous communities where multilingualism has endured are at global 'peripheries'; the edges of imperial, colonial and globalizing projects (May 2016; Pietikäinen \& Kelly-Holmes 2013; Silverstein 2015). In researching Indigenous multilingualisms, it has typically been a challenge for researchers to 'unlearn' assumptions about how social and linguistic groups map onto one another (Merlan 1981) due to their often unconscious commitment to linguistic nationalism (Irvine and Gal 2000). There are still many open questions about the dynamics of Indigenous multilingualisms:

- How is sociolinguistic distinctiveness projected onto language?

- How are language boundaries maintained and regimented?

- What is the role of variation in intensely multilingual societies?

- How does multilingualism influence the shape of languages? 
- How have other aspects of culture interacted with language?

In this special issue, these concerns are raised across diverse regions and contexts within Australia, Africa, North America, South America, and the Arctic. Long-standing patterns of multilingualism play into more recent processes and discourses around development and identity politics (Singer 2018). Considering studies of language maintenance and loss, Silverstein (1998) notes that "the ideological aspect of analysis is central and key to understanding how people experience the cultural continuities and interruptions in the particular case" (1998: 420). There is a great deal to be gained through closer attention to language ideologies and practices, and in particular, there is a need to develop theoretical approaches to Indigenous multilingualism in order to better understand how languages and language ecologies change within these contexts.

\section{Multilingualism across time and space}

The work in this collection sits fundamentally at the intersection of longstanding local systems of multilingualism and the more recent linguistic pressures of (post)colonialism and globalisation. The eight papers give diverse accounts of the outcomes of these critical, transitional moments for Indigenous language ecologies, and, considered together, provide a rich picture of the commonalities and divergences in Indigenous multilingualisms across the world. In section 2.1, we draw together significant and recurring themes about how multilingualisms are transformed over time, in response to pre- to post-colonial transitions but also to broader global shifts that increasingly impact the 'periphery' (Pietikäinen \& Kelly-Holmes 2013). These changes have reflexes across both language practice and ideology, and are implicated in shaping processes of language contact, variation and change. Section 2.2 considers more closely the pressures acting on language contact and variation within multilingual ecologies, revealing tensions between convergence and differentiation within and across language boundaries.

\subsection{The fate of pre-existing multilingualism under colonial pressures}

When we consider Indigenous multilingualism, we ought not to conjure the idea of a single homogenous type of language ecology. On the contrary, the cultural systems which fall under this umbrella are extremely diverse: hence Indigenous 'multilingualisms'. The outcomes of these ecologies under the manifold pressures of colonialism are equally diverse. As this collection of papers demonstrates, many different scenarios may play out, and many different factors may be implicated in how the language ecology changes (although that the language ecology will change in some way seems to be one of the few shared features). Commonly attested colonial and post-colonial linguistic ecological effects include:

- language loss: local Indigenous language(s) cease being used

- language shift: community of speakers changes from using one language to using another

- $\quad$ shift may be to coloniser or global language, or to another local language

- continuing and new multilingual practices:

- use of traditional languages alongside newer arrivals

- continuation or emergence of code-switching practices, receptive multilingualism 
- emergence of a lingua franca: some linguistic variety functions as a means of communication between people who do not share a native language ${ }^{1}$

- may be a local traditional language, a contact variety, or some other language (e.g. a global language like English)

- language contact:

- processes such as borrowing, convergence, restructuring, simplification and levelling

- emergence of new contact varieties: via, for example pidginisation, creolisation, language mixing, koineisation

- emergence of di/polyglossia: a local language ecology becomes more hierarchical, with certain languages developing domain specialisation or evaluations of greater prestige

This list is of course non-exhaustive, and these scenarios are not mutually exclusive; for example, language loss typically implicates language shift, and increasing use of a contact variety may well signal emerging diglossia. In this issue, we have focused our attention on communities where more than one Indigenous language has continued to be spoken, such that multilingualism between these languages persists and the effects listed above play out in varied ways.

In the northern Australian contexts depicted in the papers by Rumsey, Singer and Vaughan, traditional multilingual systems have adapted variously to the arrival of English and the spread of the contact varieties that subsequently developed. At Warruwi (Singer) and Maningrida (Vaughan), very high levels of multilingualism endure but have been reshaped in response to a range of demographic, cultural and linguistic shifts, especially changing patterns of mobility and residence. All three northern Australian ecologies featured have adapted to accommodate English, with localised Aboriginal Englishes now learned by some individuals from birth, alongside other codes. Closer inspection reveals regional diversities, however, such as the presence of Torres Strait Creole at Warruwi and Burarra-English codemixing at Maningrida emerging as a highly localised lingua franca. Traditional language allegiances are, in contemporary contexts, adhered to via various linguistic strategies, such as performative public language choices and the use of receptive multilingualism (Singer), whereby speakers do not accommodate to the language of their interlocutor but rather use their own language in interactions. Receptive multilingualism may scaffold a minimisation of code-switching, a practice which - as we will see - can be ideologically inhibited (Singer, Epps). Receptive multilingualism is evidently a common strategy in such contexts where language allegiance is important and expected to be performed in interaction; in Epps' paper depicting the Vaupés of northwest Amazonia, such 'passive multilingualism' is described as a regional norm, while in Pietikäinen's work on Arctic Finland, this mode is drawn on in daily Sámi interactions and educational contexts, and is collaboratively scaffolded by conversational participants.

In each of the volume's papers, a pre-existing multilingual system has undergone transformation following colonial contact. In most cases, certain traditional languages within the former ecology have not survived the transition, or are now severely endangered (e.g. Uru in the Andean altiplano (Narayanan), Manangkardi and Amurdak in north-west Arnhem Land (Singer), and Keminsaami in Arctic Sámiland (Pietikäinen)). Many contexts retain strong reflexes of earlier local diversity, as in the northern Australia examples. In the Amazonian Vaupés region, a 'traditional' diverse 'regional system' (e.g. Sorensen 1967,

\footnotetext{
${ }^{1}$ Our thanks to a reviewer who notes that this is by no means limited to colonial or post-colonial settings; one example of a pre-colonial lingua franca is the development of Hiri Motu in New Guinea.
} 
Aikhenvald 2002) persists, but now accommodates relative newcomers Nheengatú, Portuguese, and Spanish, with all groups interacting regularly (Epps). Arctic Sámiland is still home to nine Sámi languages, although one (Northern Sámi) is dominant, and all speakers also have Finnish, Swedish, Norwegian, English, or Russian in their repertoires (Pietikäinen), and while the ecology of Casamance remains broadly egalitarian, dynamics between languages have shifted over time in response to population changes (Watson). In north-east Arizona, the Tewa still partially maintain multilingualism between their own Tewa language and neighbouring Hopi, and now also include English in their repertoires, but in Central California the Mono language has been only recently centralised as emblematic of group identity among speakers who have largely shifted to English, as compared to a former more utilitarian approach to speakers' Indigenous multilingual repertoires (Kroskrity). Similarly, in Puno (Peru), Quechua and Aymara have become unique essentialised indexes of their respective ethnic groups, with the historical diversities and multilingualism between the groups now largely obscured by discourses of boundary maintenance (Narayanan). While language hierarchies and indexicalities may be altered or renegotiated in the wake of colonialism, outcomes are also shaped by pre-existing relationships between Indigenous languages, such as the imbalances between forest and riverine groups in Epps' paper, and the cultural and political capital of Sámi languages in Pietikäinen's.

Although not the focus of the papers in this volume, it is important to note that colonial interactions have commonly resulted in the development of new contact varieties, such as pidgins, creoles and mixed languages. The Australian context provides ample evidence of the emergence of English-lexified Indigenous languages following invasion and colonisation in 1788: Kriol originates in Queensland Pidgin English and New South Wales Pidgin and now localised varieties are in daily use across northern Australia, while Torres Strait Creole, spoken predominantly in the Torres Strait and the north-western Cape York peninsula (but also found, for example, at Warruwi (Singer)), finds its roots in Melanesian Pidgin English and Kanaka English (Meakins 2014). Aboriginal English varieties spoken throughout Australia draw on diverse local and regional sources, but show significant convergence across the country (Eades 2014; Malcolm 2008).

The outcomes of contact may affect the deployment of not only multilingual repertoires but also multilectal ones, i.e. the ways in which lects pattern within a single language. Vaughan's paper exemplifies the ways in which variation within a language, in this case Burarra, may be given new dimensions in response to changing mobilities and social goals, and shift from more localised to supra-local indexical categories. Singer's work at Warruwi further demonstrates the increasing role of certain remote Indigenous communities as the reference point of identity performance, with individuals identifying strongly with particular townships, alongside more traditional systems of land-based indexical practice (see also Watson's work on Casamance villages). Such community-centred indexes may equally attach to language-internal variation (e.g. in Burarra) or to entire codes (e.g. Mawng at Warruwi).

A number of the papers follow the development and ongoing regional use of lingua francas - some linguistic variety which comes to be used as a means of communication across groups without a native language in common. This kind of scenario is a commonplace strategy across the world in response to rapid social and linguistic change. Both papers from South America describe the reification of particular Indigenous languages as lingua francas or lenguas generals. In the Andean altiplano, linguistic diversity was a challenge to administration and religious conversion and so languages like Aymara, Puquina, Mochica, and especially Quechua were used in colonial documents and interactions (Narayanan). In the Brazilian Vaupés, the Tupi-Guaranian language Nheengatú was similarly spread by priests in the colonial era, while the enforced boarding-school system, although often brutally 
promoting the use of Portuguese, created conditions for the emergence of Tukano as the language of communication outside of the classroom among the multilingual children - and later among Indigenous people in the region more generally (Epps). This emergence of a dominant local Indigenous lingua franca often foreshadows an eventual shift to a colonial language - a commonly attested 'stepping-stone' model of language shift (Epps) in Brazil, Colombia and beyond.

Certain local contexts, however, have been more resistant to the emergence of a lingua franca. It has been observed that in Maningrida, northern Australia, a lingua franca never emerged, 'against the odds' of high levels of local linguistic diversity and multilingualism, and that instead many Indigenous languages are still maintained and in daily use. Local configurations of demographic and socio-historical factors shaped this outcome, of course, but it seems that various long-standing communication strategies and language ideologies in the region also scaffolded the maintenance of diversity and the lack of a lingua franca (Vaughan, Watson observes a similar connection in Casamance). Most of the language ecologies represented in this volume have some characteristics of 'egalitarian' or 'smallscale' multilingualism - systems where multiple languages are prototypically spoken by small groups of people who are multilingual in each other's languages, and where the languages are not subject to a strict social hierarchy or domain separation (Francois 2012; Lüpke 2016; Singer \& Harris 2016). Many local ecologies have, post-contact, however, developed aspects of a di/polyglossic system whereby certain codes are differentiated by domain or within a social hierarchy. In Maningrida this is exemplified by the emergence of Burarra-English code-switching as a code associated with certain community domains. In Casamance, polyglossia now exists insofar as French, the ex-colonial language, is characteristic of officialdom (Watson), while in Arctic Sámiland, seasonal multilingualism has emerged from changing socioeconomic dynamics and mobility, with various international languages now prevalent in tourist domains at certain times of the year (Pietikäinen).

The fate of long-term multilingualism under colonial pressures is shaped by preexisting and emergent language ideologies (e.g. Irvine and Gal 2000; Kroskrity 2004), or language ideological 'assemblages' (Kroskrity) - complexes of beliefs and feelings about language, and ontologies about how language interacts within a broader sociocultural system. Language practices and ideologies are understood in each paper to be "mutually constituting" (Nakassis 2016). The papers discussing Australian multilingualism, and the papers by Kroskrity and Epps especially, connect the observable outcomes within multilingual systems to pre-existing local language ideologies, some of which persist vigorously post-contact. These ideologies tend to foreground essentialised connections between language and territory (Watson's 'ideological home base', see also Lüpke 2017), or language, inheritance and lineage - which are typically tightly connected. In the Vaupés, as in northern Australia, individuals are expected to use their father's (or father's father's) language - the 'patrilect'. Speakers are understood to have 'true' knowledge only of this variety, while use of another may be viewed as mere imitation. Despite the inherent quality of the patrilectal connection, it must nevertheless be continually performed and constructed in interaction. The matrilect may also be ideologically central, but not necessarily spoken - in some Vaupés communities "a proper relationship to one's matrilect is to understand it... but not to speak it" (Chernela 2013). This contrast between 'use' and 'understanding, or 'speaking' and 'hearing', may be considered in itself a kind of language ideology (Singer) which points to the different relationships an individual is expected to have to the languages within their repertoire.

More broadly, a common theme among the papers is the functioning of language as an essential emblem of group identity, a function which can contribute to a language's resilience in the face of colonisation, but which may result in quite different patterns in multilingual practice and language contact effects from place to place. In nearby communities 
Warruwi and Maningrida, localised constellations of social and historical factors have produced quite distinct post-contact language ecologies, but nevertheless these are fundamentally shaped by similar underlying assumptions about connections between language, land and lineage. Strong indexical functions of language scaffold ideologies of distinctiveness in social practice, and are naturalised through primordial origin narratives (also discussed in the papers by Narayanan, Rumsey and Kroskrity). These indexical links may manifest in the maintenance of existing linguistic boundaries (including, for example, resistance to code-switching and borrowing (Epps)) and even in the deliberate creation of difference in linguistic practice (Vaughan), enabling language groups to "be different together" (Brown 2016: 9) within a connected regional system. This paradoxical unifying quality of diversity and difference can be understood as contributing to broader social harmony (Singer), as well as aesthetic value in cultural practice (e.g. Evans 2010). Kroskrity draws our attention, however, to the fact that the equation of language with group identity is not a given, and that this connection may be imposed through encounters with colonial ideologies. Among the Western Mono, multilingualism served largely functional ends and thus Mono was not recruited as a group emblem. In the wake of the colonial period, when the intergenerational transfer of Mono was disrupted, the long-standing utilitarian language ideology that had promoted functional multilingualism in fact facilitated the shift to English, and Kroskrity suggests the hegemonic state ideology of linguistic nationalism played a role in iconising the Mono language to group identity in the late twentieth century in a way that it had never been before (Irvine and Gal 2000). In contrast, the guiding Tewa ideologies of purism and compartmentalisation in language practice scaffolded Tewa maintenance and enabled resistance to the shift to Hopi and English.

The language ideologies circulating in contexts of Indigenous multilingualism may not always coincide; tensions are readily observable within the "whole web of intertwined discourses" that indigeneity and multilingualism provoke (Pietikäinen). These tensions are perhaps most obvious in the schisms between traditional language ideologies and those concomitant with colonising systems, which may partially or entirely obscure the former. We are shown in the paper by Kroskrity how the linguistic nationalism inherent in the state's educational policies valued a monolingual mode of engagement, thereby promoting English and reifying specific local languages as singular heritage icons, at the expense of others within the language ecology. As Pietikäinen's contribution demonstrates, these tensions may equally be brought about through interaction with processes beyond national boundaries: international indigenous political movements and globalisation processes have added complexity to existing negotiations around who may rightfully be considered Sámi, and who may learn Sámi languages. But mismatches in language ideologies are not only a product of local vs. external systems, as such divergences are also part and parcel of long-standing Indigenous ecologies. Examples abound in the papers featured here, such as in the competing scalar projects of unity and distinction in the papers by Narayanan and Vaughan, and the tensions between ideologies of linguistic purity and utilitarianism/variationism in those by Kroskrity and Watson.

\subsection{Competing pressures in language contact and variation}

Longstanding multilingual ecologies like the ones featured in this volume provide fertile ground for exploring the dynamics of language contact between both closely related and typologically diverse varieties, and language variation and change within individual languages and lects. In this section we consider some key open questions about the dynamics of Indigenous multilingualisms worldwide: how language boundaries are maintained and 
regimented, how salient socio-cultural categories are projected into the language space, and how variation functions in intensely multilingual societies.

The operation of language variation and change in multilingual Indigenous regional systems can seem at first glance to exhibit competing, even contradictory pressures. On the one hand, diffusion resulting in supra-local convergences of linguistic features appears commonplace, as noted in the papers by Epps, Rumsey, Vaughan and Watson especially. On the other hand divergence, and perhaps even deliberate differentiation, is readily observable in inter-group linguistic practice in these same contexts. In fact, many highly multilingual ecologies around the world are characterised by this very tension between contact-induced diffusion and the ongoing construction and performance of difference. The development of areal features is commonly connected with intensive multilingualism; given time, convergence may occur between codes within individual speakers' repertoires and effect language change at the regional level. In Rumsey's paper, patterns of diffusion within the Worrorran family of the Northern Kimberley are taken as evidence of longstanding multilingual practices in the region. In this scenario the languages involved are closely related, but this is not always the case: further east in Arnhem Land, extensive grammatical, phonological and lexical diffusion has occurred across a major genetic boundary (PamaNyungan/non-Pama-Nyungan) (Vaughan, see also Heath 1978, 1981), as has been the case among the four language families of the Vaupés region (East Tukanoan, Arawakan, Naduhupan, Kakua-Nukakan) (Epps). Where power relations between groups are relatively balanced or neutral, we may expect more even patterns of diffusion, while unequal relations such as those that typify Indigenous/coloniser interactions are likely to be more unidirectional (Epps, Watson, see also Aikhenvald and Dixon 2001).

The papers from Epps, Rumsey and Vaughan point to an interesting divergence in diffusion effects: while structural diffusion - that is the spread of grammatical categories and structures - is patently extensive in the regions discussed, the lexicons of Indigenous languages have been partially or entirely resistant to such pressures, and hence lexical borrowings are more constrained. This is not an entirely novel observation, as similar contact outcomes are reported in work profiling multilingual Indigenous contexts across the world, such as in Gumperz and Wilson's (1971) seminal work on Indo-Aryan/Dravidian contact in Kupwar, central India (see also, e.g., Dimmendaal 2008, François 2012, Harvey 2014, Ross 2001). Thus in the Vaupés, as in parts of northern Australia and the Casamance, local multilingual dynamics and ideologies scaffold the maintenance and performance of linguistic distinctions on certain levels while favouring their erasure on others. Rumsey argues that the outcomes of contact between Worrorran languages reflect speakers' levels of awareness of different aspects of language (Silverstein 1981). Conscious awareness of words as a unit of language means speakers resist borrowing them across perceived language boundaries, but aspects of grammar and phonology may pass under their radar and converge as a result of contact.

Diffusion is one area in which Indigenous language contact and colonially-mediated contact show major differences. While structural influence has been profound among some of the Indigenous language systems described above, borrowing of grammatical categories and structures has been much more limited between Indigenous languages and colonial ones due in part to the differing time-scales of contact, but also to differing patterns of multilingualism and ideologies guiding these practices. These Indigenous vs. coloniallymediated divergences also extend to lexical borrowing, which appears to be more free between Indigenous and colonial languages (although largely unidirectional), and also to code-switching practices. For example, code-switching between Portuguese and Hup is quite acceptable in some contexts, while code-switching between Hup and other Indigenous languages is not (Epps, see also Good and Di Carlo forthcoming and Vaughan in press). Epps 
comments that these "may in fact be relatively standard outcomes of intense, long-term multilingualism in small-scale social contexts" although they are somewhat surprising compared to the findings of many studies of language contact. Myers-Scotton's important and influential work on code-switching, for example, is largely premised on the assumption that "all linguistic varieties in a community are rarely treated equally", and her scenarios for typical bilingual situations reflect this assumption (2002: 31-35) (see also discussion in Harvey 2011). As we have seen, such di/polyglossic models of multilingualism are not reflective of most Indigenous language ecologies pre-contact, and so the code-switching literature has much to learn from the real diversity of historical and contemporary multilingual systems.

The volume's papers all address variation in some sense, with some looking at finegrained variation, such as Rumsey, Vaughan and Watson, and others focusing on the use of different languages. Vaughan's paper describes the operation of elaborated systems of variation within Arnhem Land languages, languages that also show extensive diffusion. These processes can be considered a form of 'ausbau' (Garde 2008, Kloss 1967) - deliberate elaboration of languages to create distance and distinction between groups for particular social goals - a process normally understood to be the purview of languages representing institutions like nation states, but seen here operating among much 'smaller' languages as well. The question of speaker/community agency in creating such linguistic differentiations is a difficult one, and calls to mind the notion of the 'invisible hand' in shaping language structure (Evans 2003, Garde 2008, Keller 1994).

The level of distinctiveness required for speakers in these communities to posit different languages is not predictable. Vaughan explores some of the ways in which varieties of Burarra have been classified by linguists and by speakers. Although there seem to be limited differences between the varieties, speakers may still consider them separate dialects, or even distinct languages. Narayanan, Kroskrity and Singer look at situations in which very different languages are spoken within the one community so the recognition of language boundaries is less variable across viewpoints between linguists and speakers. Community perceptions of the boundaries between codes are drawn upon in the regimenting and deployment of code-switching practices (or indeed their avoidance). A number of papers explore how different languages are used, mixed, or kept separate across contexts of use. Kroskrity considers the ceremonial delineation of codes in a largely Hopi community where a small group continue to maintain the Arizona Tewa language as well. Singer looks at how ideologies of linguistic purism play into code-switching practices in a community where almost everyone speaks more than one language, and compares different conversations between the same pair of speakers. In one case, one speaker mixes two languages, but in another sticks with one for the entire speech event. Spoiler: the formality of the context is important.

These inherent tensions between observed commonality and performed differentiation in linguistic practice are navigated in several communities in the volume through a certain fluidity and flexibility in identification and boundary making. Across the papers we see that labels for varieties and categories may act as 'shifters', "as notional and ideological reference points" (Lüpke 2015: 5), and that individuals may affiliate differently on different occasions, drawing on various indexical tools - linguistic and other - to serve their intentions in interaction. Strict 'linguistic coherence' (Guy, 2013; Guy and Hiskens, 2016) within codes may not be necessary for achieving indexical recognition (Vaughan, Watson). Pietikäinen's work, however, demonstrates the potential implications of fixing and reinforcing boundaries of language and identity: regimes of recognition emerge wherein "there are always winners and losers, turning language and identity category production into a question of power and inequality". 


\section{Theorising multilingualism(s)}

The analyses in the papers draw on ideas from both anthropology and linguistics, in particular the tightly interwoven subfields of sociolinguistics and linguistic anthropology (Coupland 2016). Contemporary anthropology lacks a single overarching theory, as does linguistics, so it is not surprising that the authors draw on a diverse range of concepts and frameworks to examine and illuminate their object of study. Within qualitative sociolinguistics there is one, very widely-used theory of societal multilingualism: the 'domain-separation' model centred around the notion of a polyglossic society that originates with Fishman (1967). However, the contexts examined in this special issue do not fit the polyglossia model well. This special issue aims to do some of the groundwork towards developing alternative models of multilingualism. Each paper points out different ways that the polyglossia model fails to apply, and taken together they suggest what a model of non-polyglossic multilingualism might look like. At this stage, it is not yet clear whether the Indigenous multilingualisms described in the papers could all be encompassed by a single model of non-polyglossic multilingualism, or whether multiple models are needed.

Accommodation is a key concept in sociolinguistics, claimed to be universal because it is grounded in a psychological predisposition to prefer that which is more similar to oneself (Shepard, Giles \& Le Poire 2001). A number of the papers in this issue challenge the assumption that accommodation is universal and suggest that in many communities the tendency to accommodate is balanced by ideologies of differentiation. Singer's paper discusses receptive multilingualism, which is not only widespread at Warruwi Community but, she argues, integral to the maintenance of multilingualism there. Receptive multilingualism, in which each interlocutor sticks with a different language, requires resistance to accommodating to the other interlocutor as well as minimisation of codeswitching. Epps provides evidence that in the northwest Amazonian Vaupés region many hold the view that in order to be true to one's own ethnicity, people should only use their patrilect in their home community, where it is one of a range of languages that are widely understood. This pattern has limits as "outside the community patrilectal loyalty is balanced with accommodation to interlocutors, relative to seniority". The need to differentiate oneself from people with different ethnic identities is just as important as the need to appear similar to those with one's own ethnic identity, which drives accommodation.

Issues related to the speech community and its conceptualisation come to the fore in many papers. The speech community is an enigma, recognised as a key concept in sociolinguistics, but still often ignored in practice (Rampton 2010). Epps' study suggests that there are various levels to the speech community that Hup speakers move in. The community within which people can use their patrilect is, according to local norms, a smaller one, nested within a wider one that speakers participate in, in which they have to accommodate to use the languages of the more politically dominant riverine people. Each paper in this issue sketches different conceptualisations of the speech community, understood here as a 'middle space' in which the understandings of the researcher and the research participants are integrated. Vaughan shows how languages are projected into geographic space pointing out how discontinuities as viewed by linguists, such as the boundaries of language families, may fail to line up with boundaries identified by speakers, who can prioritise cultural affiliations. Because speech communities are part of the study design, they build on notions of similarity and difference among research participants but, crucially, they are not emic constructs. Watson points out that the boundary of the 'Crossroads' area - the three interconnected villages that she studies - is somewhat arbitrary and thus to fully understand the circulation of lexemes, we also need to look at the wider region, including quite distant language varieties. 
The study of language ideologies involves investigating the way people talk about language, but because such talk is never purely about language the ideologies always connect language use to broader discourses, which generally have a political dimension (Pietikäinen, Kroskrity and Narayanan). Across the papers, we see that some language ideologies are surprisingly widespread and these could form part of a model of non-polyglossic multilingualism. Most papers find that speakers of Indigenous languages identify with a single language they state allegiance to through male ancestors. This kind of language ideology goes against assumptions about the primacy of the 'mother tongue' in much multilingualism research. Language socialisation in the settings discussed here often has a strong focus on avoiding using the mother's language and instead using the father's. The other key language ideology that emerges from these papers is of course linguistic nationalism - a powerful, pervasive, virtually inescapable ideology that is, however, more often discussed in analyses of language and the state. Here the same processes we are familiar with play out on a much smaller stage (cf. Garde 2008). A model of non-polyglossic multilingualism needs to encompass the range of ways linguistic nationalism is expressed at a smaller scale where groups are often overlapping, fluid and not clearly defined.

Existing multilingualism theory provides only limited insight into the Indigenous multilingualisms brought to light in this special issue, as multilingualism is largely theorised in terms of polyglossia. Fishman (1967) proposed polyglossia as just one kind of societal multilingualism but because no other kind of societal multilingualism has ever been elaborated into a fully-fledged model, alternatives are rendered invisible by the ubiquity of Fishman's model. New models of non-polyglossic multilingualism could greatly aid the study of small-scale speech communities - although it seems doubtful that a single model could do justice to the varied societal multilingualisms discussed in this issue. Kroskrity compares two Indigenous north American contexts, constructing models of multilingualism for each that highlight the deep differences; Epps discusses 'regional systems', but points out that "generalizations may obscure the fine detail of diversity in this region"; and Watson points out the value of focus on micro-regions, showing diversities within diversity.

A recent focus on Indigenous multilingualism around the world has led to various ideas starting to attach to terms such as 'non-polyglossic multilingualism', 'egalitarian multilingualism' or 'small-scale multilingualism' (Francois 2012; Lüpke 2016). New models of multilingualism that can encompass the kinds of features we may observe in the communities profiled here will need to incorporate key concepts from sociolinguistics and linguistic anthropology, such as the speech community and language ideologies, to pinpoint exactly how non-polyglossic multilingualisms differ from what has been described elsewhere.

\section{Acknowledgements}

Our sincere thanks to the audience for their helpful discussion at the 'Evidence of 'preexisting' multilingual ecologies in contemporary Indigenous language ideologies and practices' workshop at the American Anthropological Association Annual Meeting in 2016, and to our discussant Michael Silverstein for his insightful and generous feedback on the papers, all of which are also in this special issue.

\section{References}

Aikhenvald, A. Y., 2002. Language Contact in Amazonia. Oxford University Press, Oxford. 
Aikhenvald, A., Dixon, R. M. W., 2001. Introduction. In: Aikhenvald, A., Dixon, Robert M. W. (Eds.), Areal Diffusion and Genetic Inheritance: Problems in Comparative Linguistics. Oxford University Press, Oxford, pp. 1-26.

Blommaert, Jan. 2013. Ethnography, superdiversity and linguistic landscapes: Chronicles of complexity. Bristol: Multilingual Matters.

Brown, Reuben. 2016. Following footsteps: The kun-borrk/manyardi song tradition and its role in western Arnhem Land society. PhD thesis, Sydney University, Sydney.

Chernela, J., 2013. Toward an East Tukano ethnolinguistics: Metadiscursive practices, identity, and sustained linguistic diversity in the Vaupés basin of Brazil and Colombia. In: Epps, P., Stenzel, K. (Eds.), Upper Rio Negro: Cultural and Linguistic Interaction in Northwestern Amazonia. Museu do Índio-FUNAI, Rio de Janeiro. pp. 197-244.

Coupland 2016

Dimmendaal, G., 2008. Language ecology and linguistic diversity on the African continent. Language and Linguistics Compass 2, 40-858.

Eades, Diana. 2014. Aboriginal English. In Harold Koch and Rachel Nordlinger (Eds), The Languages and Linguistics of Australia: A Comprehensive Guide, pp. 417-47. Berlin; Boston: De Gruyter Mouton.

Evans, N., 2003. Context, culture, and structuration in the languages of Australia. Annu. Rev. Anthropol. 32 (1), 13-40.

Evans, Nicholas. 2010. "A Tale of Many Tongues: Polyglot Narrative in North Australian Oral Traditions.” In Brett J. Baker, Ilana Mushin, Mark Harvey, and Rod Gardner (Eds), Indigenous Language and Social Identity: Papers in Honour of Michael Walsh. Pacific Linguistics 626. Canberra: Pacific Linguistics. pp. 275-95

Evans, Nicholas. 2013. Multilingualism as the primal human condition: what we have to learn from small-scale speech communities. Keynote lecture, International Symposium on Bilingualism, Singapore, 10-12 June 2013.

Fishman, Joshua. A. 1967. Bilingualism with and without diglossia; diglossia with and without bilingualism. Journal of Social Issues 23(2): 29-38.

François, A., 2012. The dynamics of linguistic diversity: Egalitarian multilingualism and power imbalance among northern Vanuatu languages. International Journal of the Society of Language 214, 85-110.

Garde, M., 2008. Kun-dangwok: "clan lects" and Ausbau in western Arnhem land. Int. J. Sociol. Lang. 191, 141-169.

Good, J., Di Carlo, P., Forthcoming. Multilingualism in Rural Africa. In: Oxford Research Encyclopedia of Linguistics. DOI: 10.1093/acrefore/9780199384655.013.227.

Gumperz, J. J., Wilson. R. 1971. Convergence and creolization: A case from the Indo Aryan/Dravidian border. In Hymes. D. (Ed.), Pidginization and Creolization of Languages. Cambridge University Press, Cambridge, pp. 151-168.

Guy, G.R., 2013. The cognitive coherence of sociolects: how do speakers handle multiple sociolinguistic variables? J. Pragmat. 52, 63-71.

Guy, G.R., Hinskens, F., 2016. Linguistic coherence: systems, repertoires and speech communities. Lingua 172-173, 1-9.

Harvey, Mark. 2011. Lexical change in pre-colonial Australia. Diachronica 28 (3): 345-81.

Harvey, M. 2014. Reconstructing long-term limits on diffusion in Australia. Anthropological Linguistics 55 (2), 158-183.

Heath, J. 1978. Linguistic diffusion in Arnhem Land. Canberra: AIATSIS.

Heath, J. 1981. A case of intensive lexical diffusion: Arnhem Land, Australia. Language 57: 335-367.

Irvine, Judith. T., \& Susan Gal. 2000. Language ideology and linguistic differentiation. In Paul V. Kroskrity (ed.), Regimes of language: Ideologies, polities, and identities (pp. 35-84). Santa Fe: School of American Research Press.

Keller, R., 1994. On Language Change: The Invisible Hand in Language. Routledge, London/New York.

Kloss, H., 1967. Abstand-languages and Ausbau-languages. Anthropol. Ling.s 9 (7), 29-41.

Kroskrity, Paul V. 2004. Language ideologies. In Alessandro Duranti (ed.), A companion to linguistic anthropology, 496-517. Oxford: Blackwell. 
Lüpke, Friederike. 2015. Denorthernising Multilingualism and Multilingualism Research. Framing Language in the North: From the Monolingual Nation State to Acknowledging (Super)Diversity. Multilingualism in the Global South (and beyond) [Special Issue]. Voices from around the World 3: 3-5.

Lüpke, Friederike. 2016. Uncovering Small-Scale Multilingualism. Critical Multilingualism Studies 4(2): 35-74.

Lüpke, Friederike, 2017. Multiple choice: Language use in rural Casamance between convergence and divergence. In: Jacqueline Knörr, Wilson Trajano Filho (Eds.), Creole Languages and Postcolonial Diversity. Oxford University Press, Oxford.

Malcolm, Ian G. 2008. Australian creoles and Aboriginal English: Phonetics and phonology. In: Kate Burridge and Berndt Kortmann (eds.), Varieties of English 3: The Pacific and Australasia, 124141. Berlin: Mouton de Gruyter.

May, Stephen. 2016. Linguistic Superdiversity as a "new" theoretical framework: Panacea or nostrum? Talk at MOSAIC, Birmingham University, 3 February 2016. Retrieved from: http://www.birmingham.ac.uk/generic/tlang/documents/linguistic-superdiversity-as-a-newtheoretical-framework.pdf

Meakins, Felicity. 2014. Language Contact Varieties. In Harold Koch and Rachel Nordlinger (Eds), The Languages and Linguistics of Australia: A Comprehensive Guide. Berlin; Boston: De Gruyter Mouton. pp. 361-411.

Merlan, Francesca. 1981. Land, language and social identity in Aboriginal Australia. Mankind 13: 133-148.

Myers-Scotton, Carol. 2002. Contact Linguistics: Bilingual encounters and grammatical outcomes. Oxford \& New York: Oxford University Press.

Pietikäinen, Sari \& Helen Kelly-Holmes. 2013. Multilingualism and the Periphery. In S. Pietikäinen \& H. Kelly-Holmes (Eds.), Multilingualism and the Periphery (pp. 1-16). Oxford; New York: Oxford University Press.

Rampton 2010

Ross, M., 2001. Contact-induced change in Oceanic languages in northwest Melanesia. In: Aikhenvald, A. Y., Dixon, R. M. W. (Eds.), Areal Diffusion and Genetic Inheritance. Oxford University Press, Oxford, pp. 134-166.

Shepard, Giles \& Le Poire 2001

Silverstein, M. 1981. The limits of awareness. Sociolinguistic Working Paper No. 84. Southwest Educational Development Laboratory, Austin.

Silverstein, Michael. 1998. Contemporary Transformations of Local Linguistic Communities. Annual Review of Anthropology 27(1): 401-426.

Silverstein, Michael. 2015. How language communities intersect: Is "superdiversity" an incremental or transformative condition? Language \& Communication 44: 7-18.

Singer, Ruth. 2018.

Sorensen, A. P. Jr., 1967. Multilingualism in the northwest Amazon. American Anthropologist 69, 670-684.

Vaughan, Jill. In press. Translanguaging and the construction of difference in north central Arnhem Land. In G. Mazzaferro (ed), Translanguaging in Everyday Practice. Dordrecht: Multilingual Education Series, Springer.

Vertovec, Steven. 2006. The emergence of super-diversity in Britain (Working paper 25). Centre on Migration, Policy and Society. Oxford: Oxford University. 